O editor deste livro, Louis J. Ignarro, foi um dos ganhadores do Prêmio Nobel em Fisiologia e Medicina, em 1998, devido às suas descobertas relacionadas às funções do óxido nítrico no sistema cardiovascular. Neste livro, o Dr. Ignarro reuniu 134 colaboradores de diversos países, que produziram um tratado que abrange todos os aspectos conhecidos sobre o óxido nítrico, desde a sua produção, química, bioquímica, transporte, aspectos fisiológicos, participação na sinalização intracelular e implicações fisiopatológicas. O livro tem 58 capítulos, que são divididos em três partes principais, a saber: Princípios Básicos (1), Princípios da Biologia (11) e Princípios da Patobiologia (HI). A parte 1 compreende um capítulo, no qual são abordados fundamentos básicos sobre a bioquímica e fisiologia do óxido nítrico. A parte 11 é subdividida em seis grandes temas, incluindo: (A) Química Biológica, (B) Óxido Nítrico Sintases, (C) Regulação da Produção de Óxido Nítrico, (D) Transporte, Interação com Membranas e Transporte de Oxigênio, (E) Óxido Nítrico e Estresse Oxidativo e (F) Mecanismos de Transdução de Sinal, com um total de 25 capítulos. Na parte M, formada por 32 capítulos, encontram-se outras quatro áreas temáticas, a saber, (A) Óxido Nítrico e o Sistema Nervoso Central, (B) Óxido Nítrico e a Função Cardiovascular, (C) Mecanismos Fisiopatológicos do Óxido Nítrico e (D) Significado Clínico do Óxido Nítrico. Todos os assuntos são abordados com profundidade, clareza e atualidade e as ilustrações, de excelente qualidade, facilitam a compreensão do texto. A bibliografia, citada ao final de cada capítulo, é bastante útil para aqueles que queiram aprofundar seus conhecimentos específicos nos diversos tópicos abordados. Esta é uma obra imprescindível para todos aqueles que atuam na pesquisa básica e aplicada, cujos temas de interesse estejam relacionados ao óxido nítrico.

Profa. Dulcineia Saes Parra Abdalla FCF/USP

\section{QUIMICA FARMACÊUTICA}

BANNWARTH, W., FELDER, E., eds. Combinatorial chemistry: a practical approach. Weinheim: Wiley-VCH, 2000. 430p.

Este compêndio discute, de forma bastante completa, assunto de grande interesse na área de planejamento e síntese de novos fármacos: a química combinatória, empregando métodos computacionais. Mediante utilização deste procedimento, a obtenção de novos modelos torna-se acelerada em relação aos métodos clássicos. Permite a

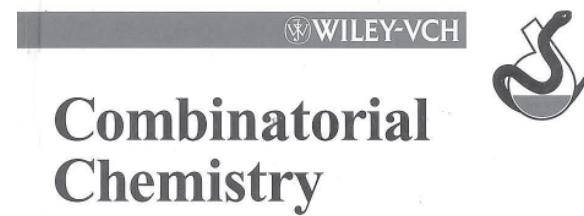

A Practical Approach

Edited by Willi Bannwarth and Eduard Felder

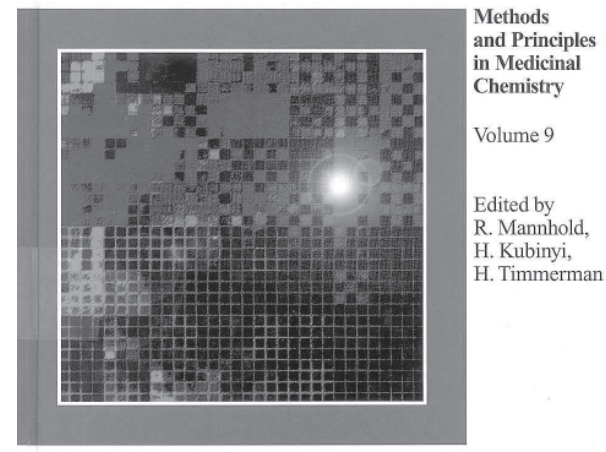

manutenção das chamadas bibliotecas de novos derivados, que, a qualquer momento, poderão ser empregados. Por outro lado, torna-se fácil a obtenção de agentes inéditos aplicando métodos sintéticos e biológicos mais rápidos $\mathrm{e}$ acessíveis. Outrossim, discute a química de fase sólida como recurso importante para a produção, em escala rápida, de múltiplas cópias. Alerta para as vantagens e desvantagens do processo. Como foi escrito por especialistas renomados, que de fato atuam na área, traz minúcias sintéticas, apresentando mecanismos de reações e equipamentos utilizados. Para se ter idéia da dimensão e importância da obra, os assuntos tratados nos capítulos são: I-Introdução geral; 2-Química Combinatória em Solvente; 3- Química em Fase Sólida (quase metade da obra); 4-Reagentes em Suportes Poliméricos; 5- Estratégias Para a Formação de Bibliotecas Combinatórias; 6-Automação e Acessórios Para Química em Fase Sólida e Síntese Orgânica Paralela (incluindo fotos e detalhes técnicos de equipamentos); 7Planejamento de Biblioteca Computacional; 8-Reações Orgânicas em Fase Sólida: Revisão Bibliográfica de 1978 a 1998. Todos os capítulos, especialmente o último, são sucedidos de farta citação bibliográfica, totalizando mais de 1300 referências. Não resta dúvida tratar-se de obra de fundamental importância a todos aqueles que atuem, não só na área farmacêutica, mas também na área das ciências de materiais. Fundamental para especialistas e alunos de pósgraduação em Farmácia.

Profa. Dra. Maria Amélia Barata da Silveira FCF/USP 